\title{
Preparation of Industrial Noise Mapping and Improvement of Environmental Quality
}

\author{
Tarık Serhat Bozkurt ${ }^{1}$ (D)
}

Accepted: 27 May 2021 / Published online: 9 June 2021

(C) The Author(s), under exclusive licence to Springer Nature Switzerland AG 2021

\begin{abstract}
Environmental noise control is necessary for human health and auditory comfort conditions. In this respect, it is required that industrial noise should be kept under control and healthy living spaces should be obtained in residential areas. This paper aims to explain industrial noise control at urban and building scales. In this study, the strategic noise mapping process related to industrial activities in a line with the Environmental Noise Directive (END) was clarified. Besides this, what type of factors are effective in the industrial noise mapping process were defined, and important basic parameters, which are essential in the industrial noise mapping, were detailed. The preparation of the industrial noise mapping process was explained in detail. It was mentioned that the regions exposed to excessive noise should be defined according to the strategic noise map and improvement plans should be performed. Improvement methods that reduce excessive noise in living spaces are clarified and it was explained how the improvement of environmental quality can be acquired. In this regard, this paper gives information on industrial noise mapping and industrial noise control at the urban scale.
\end{abstract}

Keywords Environmental noise and health $\cdot$ Industrial noise mapping $\cdot$ Improvement of environmental quality $\cdot$ Sound barrier

\section{Introduction}

At the urban scale, environmental noise should be kept under control to provide auditory comfort conditions. In the twentyfirst century, with the developing urbanization and industry, environmental noise problems have started to emerge more frequently. Control of environmental noise has great importance in terms of human health as well as providing auditory comfort conditions. The World Health Organization states that noise is the second largest environmental cause of health problems [1]. Exposure to excessive noise can cause hearing loss and excessive noise can negatively affect human health not only physiologically but also psychologically. The major physiological effects caused by noise are muscle strains, stress, increased blood pressure, changes in heart rate and blood circulation, dilated pupils, and sleeplessness. The main

This article is part of the Topical Collection on Noise Pollution

Tarık Serhat Bozkurt

bozkurtt@itu.edu.tr

1 Department of Architecture, Istanbul Technical University, Istanbul, Turkey psychological effects of noise are nervousness, fear, discomfort, anxiety, fatigue, slow mental activity, and a decrease in work efficiency [2].

The negative effects of environmental noise on human health are frequently encountered in literature studies. In the research of Farooqi et al. [3], survey analyses were done, and according to the survey results, it was stated that most of the participants exposed to the noise experienced headaches, sleeplessness, hypertension, and stress. Murphy et al. [4] stated that noise negatively affects public health. The World Health Organization [1] states that noise is effective on sleep, has cardiovascular and metabolic effects, is effective on cognitive impairment, and is effective on hearing loss and tinnitus. Arbaoui et al. [5] reported that noise exposure can cause hearing problems, hypertension, heart disease, and sleep disturbances. Alsina-Pagès et al. [6] stated that in recent years, many researchers aimed at noise reduction to avoid various adverse health effects such as sleep disturbance, discomfort, cardiovascular effects, learning impairment, and hypertension. Bozkurt and Demirkale [7] stated that environmental noise can significantly affect public health and have a remarkable impact on human activities. Sheikh et al. [8] stated that excessive 
noise affects hearing loss. Farooqi et al. [9] pointed out that excessive noise causes high blood pressure, heart disease, and headache. Basner and McGuire [10] examined the effect of noise on sleep and stated that noise decreases sleep continuity, decreases total sleep time, and causes fragmented sleep. Lercher [11] mentioned that industrial noises affecting residential areas may be highly heterogeneous due to the different activities that exist and industrial noise includes a mix of tonal, impulsive characteristics, and low-frequency noise. Besides, Lercher stated [11] that the industrial noise entering residential areas caused to reveal higher annoyance responses in general when the ambient noise level is low. Butorina et al. [12] stated that industrial noise is a cause of professional diseases that affect workers' health during the production process and about $7 \%$ of workers suffer from work-related hearing difficulties.

The European Parliament published Directive 2002/49/EC to keep environmental noise under control [13]. Analysis methods of environmental noise, preparation of noise maps, and preparation of action plans for noise measures were explained in the 2002/49/EC directive. In this directive, it was stated that the preparation of the noise map is required for all EU member states and national action plans to reduce environmental noise should be developed for each member state. Also, EU member states should report the acoustic situation and update the reported information every 5 years [13]. Today, noise originating from transportation (motorway noise, airport noise, and railway noise), noise originating from industrial activities, noise caused by construction activity, and noises caused by people and activities are effective in the formation of environmental noise. Highway noise mapping studies, railway noise mapping studies, and airport noise mapping studies are carried out to keep the noise generated from transportation under control [14-25]. In this research article, information about industrial noise control and industrial noise mapping studies is given.

It is seen in the literature that industrial noise sources differ according to production processes. Compressor noise is frequently encountered in industrial facilities and production processes. Arbaoui et al. [26] investigated the effect of two different compressor noise on environmental noise at the factory site in the north-west of Algeria. Mendonça and Leite [27] examined a factory belonging to the metallurgical industry and analyzed the noise generated by the press machines. Seutche et al. [28] analyzed the thermal power plant in Cameroon, located in the city of Mbalmayo, and defined diesel motor systems, electric generator systems, and cooling fan systems as the types of noise sources that can be found in the thermal power plant. Tomoze1 et al. [29] examined the noise sources in the textile factory and showed sewing machines, embroidery machines, automatic cutting machines, and winding machines as noise sources in the factory. Lim et al. [30] stated in their research that pressing, molding, curing, cutting, and packaging productions were carried out in the examined rubber production process of the rubber production factory in Malaysia. Bozkurt and Demirkale [7] examined the metal production facilities in Istanbul. It was stated that in the metal production process, there were different types of production activities which can be listed as foundry, turning lathe, cutting - bending metal sheets, metal stamping, and metal workshop. Arbaoui et al. [5] investigated noise pollution in urban and industrial areas of Oran located in Algeria and stated the main factors which cause noise pollution in the industrial area are rotor machines such as compressors, pumps, and turbines. The results of industrial noise levels in Oran demonstrated that noise levels were ranged from 95 to 115 dBA. Farooqi et al. [9] emphasized that different industries such as the textile industry, wood industry, and steel mills have different machines. In summary, it is understood that there can be many different types of noise sources in industrial noise analysis, and all different types of industrial noise sources may need to be considered in noise analysis.

Industrial noise problems do not only appear as environmental noise problems at the urban scale. It also appears as health problems faced by employees in industrial units. For this reason, it is essential to provide industrial noise control both at the building scale and at the urban scale. The noise exposure time of the workers in the factory is evaluated according to dose analysis. In general, daily dose analysis is carried out according to the revised standard published by National Institute for Occupational Safety and Health Standard [31]. In the revised standard, it was notified that "the amount of actual exposure relative to the amount of allowable exposure, and for which $100 \%$ and above represents exposures that are hazardous." Also, the noise exposure evaluation method was clarified and detailed in Eqs. 1 and 2 [31]. According to Eq. 3 [31], the daily dose can be converted into an 8-h time-weighted average (TWA). When the daily dose is higher than the required maximum values, workers can face health and hearing loss problems. Especially, hearing loss due to industrial noise can be observed at the $3000-$ to $4000-\mathrm{Hz}$ frequency range [2]. In the literature, too many researches are conducted about the daily dose. In the research of Ahmed and Gadelmoula [32], it was investigated to measure the occupational noise at a concrete blockmaking factory and it was determined that the daily noise dose is extremely higher than $100 \%$. 
Maheswaran et al. [33] performed the noise survey in a power press industry and it was clarified that the daily noise dose was higher than $100 \%$ for some survey points.

$\left[\mathrm{D}=\frac{C_{1}}{T_{1}}+\frac{C_{2}}{T_{2}}+\frac{C_{n}}{T_{n}}\right] 100 \%$

D Daily dose (\%) (not equal or exceed 100)

$\mathrm{C}_{\mathrm{n}} \quad$ Total time of exposure at a specified noise level

$\mathrm{T}_{\mathrm{n}} \quad$ Exposure duration for which noise at this level becomes hazardous (Eq. 2)

$\mathrm{T}_{(\text {minute) }}=\frac{480}{2^{(L-85) / 3}}$

$\mathrm{T}_{\text {(minute) }} \quad$ The exposure duration in minutes

L Exposure level (dBA)

The exchange rate (this constant is specified in NIOSH [31])

$\mathrm{TWA}=10 \times\left(\frac{D}{100}\right)+85$

TWA Time-weighted average (the 8-ho time-weighted average sound level in $\mathrm{dBA}$ )

In the directive 2002/49/EC of the European Parliament [13], noise indicators were specified and $\mathrm{L}_{\text {day }}, \mathrm{L}_{\text {evening, }}$ $\mathrm{L}_{\text {night }}$, and $\mathrm{L}_{\mathrm{den}}$ are determined to analyze noise level. Noise indicators are used to provide industrial noise control at the urban scale. Description of noise indicators and calculation methodology of noise indicators were demonstrated in Eq. 4. In the European Union, according to national requirements and needs, it is observed that maximum environmental noise levels can be identified by national authorities. In the research of Pramendra and Vartika [34], in India, Environmental Noise Pollution research is performed and the central pollution control board noise limit values were shown in their research. Comendador et al. [35] showed noise limit values in their research according to Spain local regulation. In Brazil, Zannin, and Sant'Ana [36] investigated environmental noise impact assessment based on noise mapping, and in the research, noise emission limits for several zones in Curitiba were given according to Municipal Law. In the research of Bozkurt and Demirkale [7], industrial noise mapping analyses were conducted and noise limit values for industrial areas were used according to Turkey regulation. As a result, it is understood that countries determine the maximum environmental noise levels according to their noise policies and maximum environmental noise levels can be changeable to different nations. In the EEA (European Environment Agency) report no 22/2019 [37], $\mathrm{L}_{\text {den }}$ and $\mathrm{L}_{\text {night }}$ noise indicators were used to analyze industrial activities, and European Union member nations' results were given related to industrial noise. In this report, it was mentioned that approximately 800,000 people living in urban areas are exposed to industry noise levels of at least $55 \mathrm{dBA}$ in $\mathrm{L}_{\mathrm{den}}$ period and approximately 400,000 people living in urban areas are exposed to industry noise levels of at least $50 \mathrm{dBA}$ in $\mathrm{L}_{\text {night }}$ period. It is understood that EU member nations' noise limit values are analyzed as $\mathrm{L}_{\mathrm{den}} \leq 55 \mathrm{dBA}$ and $\mathrm{L}_{\text {night }} \leq 50 \mathrm{dBA}$. Similarly, Murphy et al. [4] mentioned that in the European Commission report, approximately 1 million people were reported to be exposed to industrial noise exceeding $55 \mathrm{dBA} \mathrm{L} \mathrm{L}_{\mathrm{den}}$. Through using noise indicators, noise levels of receiver points are examined and analyzed at the urban scale.

$L_{d e n}=10 \log \frac{1}{24}\left[12 \times 10^{\frac{L_{d a y}}{10}}+4 \times 10^{\frac{L_{\text {evening }}+5}{10}}+8 \times 10^{\frac{L_{\text {nigh }}+10}{10}}\right]$

$\mathrm{L}_{\text {day }} \quad \mathrm{L}_{\text {day }}$ is the A-weighted long-term average sound level as defined in ISO 1996-2: 1987, determined over all the day periods of a year. Day period is generally defined as $12 \mathrm{~h}$, from 07:00 to 19:00

$\mathrm{L}_{\text {evening }} \mathrm{L}_{\text {evening }}$ is the $\mathrm{A}$-weighted long-term average sound level as defined in ISO 1996-2, determined over all the evening periods of a year. Evening period is generally defined as $4 \mathrm{~h}$, from 19:00 to 23:00

$\mathrm{L}_{\text {night }} \quad \mathrm{L}_{\text {night }}$ is the A-weighted long-term average sound level as defined in ISO 1996-2, determined over all the evening periods of a year. Night period is generally defined as 8 hours, from 23:00 to 07:00

$\mathrm{L}_{\mathrm{den}} \quad \mathrm{L}_{\mathrm{den}}$ is the A-weighted long-term average sound level as defined in ISO 1996-2, determined over all the day-evening-night periods of a year

Strategic noise mapping studies are carried out to control environmental noise. With strategic noise mapping studies, regions with high noise levels in the urban scale are determined and improvement decisions are made in line with the strategic noise mapping results. The strategic noise mapping process based on industrial noise will be detailed in the following section. 


\section{The Strategic Noise Mapping Process Based on Industrial Noise}

In the literature, it is observed that strategic noise maps are generally prepared in a line with noise monitoring systems and computation methods. The preparation of strategic noise maps is carried out as a result of detailed analysis and measurements. In this section, information about the preparation process of strategic noise maps will be given and the methods used in the literature will be detailed.

In large area analysis, it is seen that only noise measurements are not sufficient and the noise levels can be determined by using the calculation methods. It is understood that the noise level is calculated using the calculation method and the calculated values are verified by performing noise measurements. This section is described in three subtitles as follows.

- Calculation methodology in industrial noise mapping

- Preparing industrial noise maps with computer modeling

- Noise measurements and monitoring system

\section{Calculation Methodology in Industrial Noise Mapping}

Calculation methodology should be determined during the preparation of noise maps to obtain accurate results. In the directive 2002/49/EC [13], computation methods for the noise mapping process are clarified and for industrial noise; ISO 9613-2 standard [38] is recommended. The attenuation of sound during propagation outdoors is detailed in ISO 96132. Equation 5 is used to calculate the sound pressure level at the receiver point. Parameter A in Eq. 5 represents the sum of all of the attenuation in the sound propagation process. In the sound propagation mechanism in the free field, attenuation term $\mathrm{A}$ in Eq. 5 is calculated by Eq. 6. In the calculation of $\mathrm{A}$, all of the attenuations, which are listed as geometrical divergence, atmospheric absorption, ground effect, barrier, and other effects, should be considered. The attenuation due to geometrical divergence $\left(\mathrm{A}_{\text {div }}\right)$ is used to clarify for spherical spreading in the free field from a point source and given in Eq. 7. Equation 8 is related to the attenuation due to atmospheric absorption; the atmospheric attenuation coefficient depends on the frequency of the sound, the ambient temperature, and relative humidity of the air, and the atmospheric attenuation coefficient is clarified in ISO 9613-1 standard [39]. The ground effect varies depending on the sound absorption coefficient and characteristics of the ground. The attenuation due to the ground effect is analyzed with three different regions, which are the source region, the middle region, and the receiver region (Fig. 1a). Calculation of attenuation due to the ground effect is given in Eq. 9. Figure 1a shows different regions related to the ground effect and $h_{s}$ and $h_{r}$ means source and receiver height respectively. In Eq. 9, parameters $A_{s}, A_{r}$, and $A_{m}$ are related to ground effect and regions are the source, middle, and receiver respectively. $A_{s}, A_{r}$, and $A_{m}$ calculation methodology are given in Table 1. In Table 1, the sound absorption properties of each ground region are taken into consideration utilizing a ground factor G. In the hard ground which has low porosity, it can be considered $\mathrm{G}$ equal to $0(\mathrm{G}=0)$. The tamped ground around the industrial area can be accepted as the hard ground in the calculation process. In the porous ground which includes ground covered by grass, trees, or other vegetation, it can be considered $\mathrm{G}$ equal to $1(\mathrm{G}=1)$. In the mixed ground, the surfaces consist of not only the a)

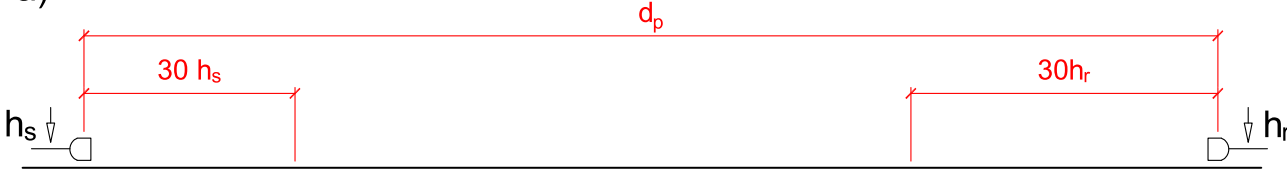

$\uparrow \quad$ Source region

c)

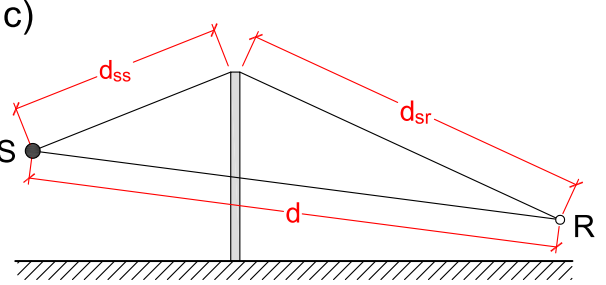

Fig. 1 Figures related to calculation methodology. a different Regions related to ground effect. b Different sound propagation paths at a barrier. c Determination of the path-length difference for single diffraction. $\mathbf{d}$, e (retrieved from ISO 9613-2 [38]) b)

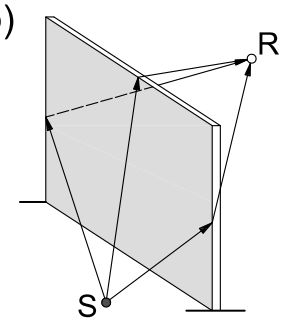

d)
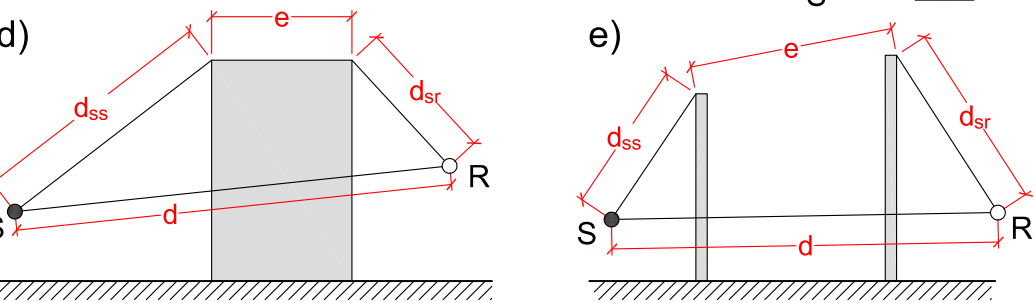

Determination of the path-length difference for double diffraction 
Table 1 According to ISO 9613-2 [38], calculating ground attenuation contributions $A_{s}, A_{r}$, and $A_{m}$

\begin{tabular}{lll}
\hline Nominal mid-band frequency, $\mathrm{Hz}$ & $\mathrm{A}_{\mathrm{s}}$ or $\mathrm{A}_{\mathrm{r}}, \mathrm{dB}$ & $\mathrm{A}_{\mathrm{m}}, \mathrm{dB}$ \\
\hline 63 & -1.5 & $-3 \mathrm{q}^{1)}$ \\
125 & $-1.5+\mathrm{G} \mathrm{x} \mathrm{a}(\mathrm{h})$ & $-3 \mathrm{q}(1-\mathrm{G})$ \\
250 & $-1.5+\mathrm{G} \mathrm{x} \mathrm{b}(\mathrm{h})$ & \\
500 & $-1.5+\mathrm{G} \mathrm{x} \mathrm{c}(\mathrm{h})$ & \\
1000 & $-1.5+\mathrm{G} \mathrm{x} \mathrm{d}(\mathrm{h})$ & \\
2000 & $-1.5(1-\mathrm{G})$ & \\
4000 & $-1.5(1-\mathrm{G})$ & \\
8000 & $-1.5(1-\mathrm{G})$ & \\
\hline
\end{tabular}

a' ( h )

$=1.5+3.0 x e^{-0.12(h-5)^{2}}\left(1-e^{-\frac{d p}{50}}\right)+5.7 x e^{-0.009 h^{2}}\left(1-e^{-2.8 \times 10^{-6} d_{p}^{2}}\right)$

$\mathrm{b}^{\prime}(\mathrm{h})=1.5+8.6 \times e^{-0.09(h)^{2}}\left(1-e^{-\frac{d_{p}}{50}}\right)$

$\mathrm{c}^{\prime}(\mathrm{h})=1.5+14.0 \times e^{-0.46(h)^{2}}\left(1-e^{-\frac{d p}{50}}\right)$

$\mathrm{d}^{\prime}(\mathrm{h})=1.5+5.0 \times e^{-0.9(h)^{2}}\left(1-e^{-\frac{d_{p}}{50}}\right)$

1) $\mathrm{q}=0$ when $\mathrm{d}_{\mathrm{p}} \leq 30\left(\mathrm{~h}_{\mathrm{s}}+\mathrm{h}_{\mathrm{r}}\right)$, q= $1-\frac{30\left(h_{s}+h_{r}\right)}{d_{p}}$ when $\mathrm{d}_{\mathrm{p}}>30\left(\mathrm{~h}_{\mathrm{s}}+\mathrm{h}_{\mathrm{r}}\right)$

where $d_{p}$ is the source to receiver distance, in meters (Fig. 1a)

porous ground but also hard ground and it can be considered $G$ values ranging from 0 to 1 .

$\mathrm{L}_{\mathrm{ft}}(\mathrm{DW})=\mathrm{L}_{\mathrm{w}}+\mathrm{D}_{\mathrm{c}}-\mathrm{A}$

$\mathrm{L}_{\mathrm{ft}}(\mathrm{DW})$ The equivalent continuous downwind octave-band sound pressure level at a receiver location

$\mathrm{L}_{\mathrm{w}} \quad$ Is the octave-band sound power level, in decibels, produced by point source

$\mathrm{D}_{\mathrm{c}} \quad$ The directivity correction (for an omnidirectional point sound source radiating into free space, $D_{c}=0$ $\mathrm{dB})$

A The octave- band attenuation, in decibels

$\mathrm{A}=\mathrm{A}_{\text {div }}+\mathrm{A}_{\mathrm{atm}}+\mathrm{A}_{\mathrm{gr}}+\mathrm{A}_{\mathrm{bar}}+\mathrm{A}_{\mathrm{misc}}$

$\mathrm{A}_{\text {div }} \quad$ The attenuation due to geometrical divergence

$\mathrm{A}_{\text {atm }}$ The attenuation due to atmospheric absorption

$\mathrm{A}_{\mathrm{gr}} \quad$ The attenuation due to ground effect

$A_{\text {bar }} \quad$ The attenuation due to a barrier

$\mathrm{A}_{\text {misc }}$ The attenuation due to miscellaneous other effects (the attenuation due to propagation through foliage, industrial sites, and areas of houses)

$\mathrm{A}_{\text {div }}=\left[20 \log \left(\frac{d}{d_{0}}\right)+11\right] \mathrm{dB}$ d The distance from the source to receiver, in meters

$\mathrm{d}_{0} \quad$ The reference distance $(=1 \mathrm{~m})$

$\mathrm{A}_{\mathrm{atm}}=\alpha \mathrm{d} / 1000$

d Propagation distance, in meters

$\alpha$ Atmospheric attenuation coefficient depends on the frequency of the sound, ambient temperature, and relative humidity

$A_{g r}=A_{s}+A_{r}+A_{m}$

$\mathrm{A}_{\mathrm{s}}$ The attenuation due to source region ground effect

$\mathrm{A}_{\mathrm{r}} \quad$ The attenuation due to receiver region ground effect

$\mathrm{A}_{\mathrm{m}}$ The attenuation due to middle region ground effect

In the analysis of the barrier, barrier surface density should be at least $10 \mathrm{~kg} / \mathrm{m}^{2}$ to obtain effective noise barrier insertion loss. In the attenuation due to a barrier, diffraction over the top edge and around a vertical edge of a barrier should take into account (Fig. 1b), the effect of diffraction over the top edge is obtained from Eq. 10 and the effect of diffraction around a vertical edge is obtained from the Eq. 11. During calculating the barrier attenuation $\mathrm{D}_{\mathrm{z}}$, it is assumed that only one significant sound propagation path exists from the source to the receiver. When this assumption is not valid, separate calculations should be performed for the other propagation paths (as demonstrated in Fig. 1b) and the contributions from the various paths are summed at the receiver points. The barrier attenuation $\mathrm{D}_{\mathrm{z}}$ is calculated utilizing Eq. 12. As given in Fig. 1c, for single diffraction, the path-length difference is given in Eq. 14. For double diffraction, as demonstrated in Fig. 1d and e, the path-length difference is calculated by Eq. 15 . The correction factor $\mathrm{K}_{\mathrm{met}}$ for meteorological conditions is obtained by using Eq. 16.

$\mathrm{A}_{\mathrm{bar}}=\mathrm{D}_{\mathrm{z}}-\mathrm{A}_{\mathrm{gr}}>0$ (for diffraction over the top edge $)$

$\mathrm{A}_{\mathrm{bar}}=\mathrm{D}_{\mathrm{z}}>0$ (for diffraction around a vertical edge $)$

$\mathrm{D}_{\mathrm{z}} \quad$ The barrier attenuation for each octave band.

$\mathrm{A}_{\mathrm{gr}}$ The ground attenuation in the absence of the barrier.

$D_{z}=10 \log \left[3+\left(\frac{C_{2}}{\lambda}\right) C_{3} z K_{m e t}\right]$ 
$\mathrm{C}_{2}$ Equal to 20, and includes the effect of ground reflections

$\mathrm{C}_{3}$ Equal to 1 for single diffraction (Fig. 1c). For double diffraction (Fig. 1d and e), $C_{3}$ is calculated by equation 13 .

$C_{3}=\left[1+\left(\frac{5 \lambda}{e}\right)^{2}\right] /\left[\left(\frac{1}{3}\right)+\left(\frac{5 \lambda}{e}\right)^{2}\right]$

$\lambda$ The wavelength of the sound, in meters

$\mathrm{z} \quad$ The difference between the path-lengths of diffracted and direct sound, as calculated by equation 14 and 15

$\mathrm{K}_{\text {met }}$ The correction factor for meteorological effects given by equation 16

e the distance between the two diffraction edges in case of double diffraction (Fig. 1d and e)

$z=\left[\left(d_{s s}+d_{s r}\right)^{2}+a^{2}\right]^{\frac{1}{2}}-d$

$\mathrm{d}_{\mathrm{ss}}$ The distance from the source to the (first) diffraction edge, in meters (Fig. 1c)

$d_{s r}$ The distance from the (second) diffraction edge to receiver, in meters (Fig. 1c)

a The component distance parallel to the barrier edge between source and the receiver, in meters

$z=\left[\left(d_{s s}+d_{s r}+e\right)^{2}+a^{2}\right]^{\frac{1}{2}}-d$

$K_{m e t}=\exp \left[-\left(\frac{1}{2000}\right) \sqrt{\frac{d_{s s} d_{s r} d}{2 z}}\right]$ for $\mathrm{z}>0$,

$K_{m e t}=1$ for $\mathrm{z}<0$

The meteorological correction $\left(\mathrm{C}_{\mathrm{met}}\right)$ is an important parameter used to acquire long-term average $\mathrm{A}$-weighted sound pressure level, where the period is several months. $\mathrm{C}_{\text {met }}$ is calculated by using Eq. 17. $\mathrm{C}_{\text {met }}$ depends on $\mathrm{C}_{0}$ which is related to local meteorological statistics. As mentioned in ISO 9613-2 [38], "Experience indicates that values of $\mathrm{C}_{0}$ in practice are limited to range from zero to approximately +5 $\mathrm{dB}$, and values in excess of $2 \mathrm{~dB}$ are exceptional. Thus only very elementary statistics of local meteorology are needed for $\pm 1 \mathrm{~dB}$ accuracy in $\mathrm{C}_{0} . "$

$$
\begin{aligned}
C_{m e t} & =0 \text { if } \mathrm{dp} \leq 10(\mathrm{hs}+\mathrm{hr}), C_{m e t} \\
& =C_{0}\left[1-10\left(h_{s}+h_{r}\right) / d_{p}\right] \text { if } \mathrm{dp}>10(\mathrm{hs}+\mathrm{hr})
\end{aligned}
$$

$\mathrm{h}_{\mathrm{s}}$ and Source and receiver height, respectively, in meters

$\mathrm{h}_{\mathrm{r}}$

$d_{p} \quad$ The source to receiver distance, in meters

$\mathrm{C}_{0} \quad$ A factor, in decibels, which depends on local meteorological statistics for wind speed and direction, and temperature gradients.

This article outlines the ISO 9613-2 standard [38] but ISO 9613-2 standard has content that is much more comprehensive. The most influential factors in the noise mapping process specified in the ISO 9613-2 standard are summarized. In the industrial noise mapping process, the determination of suitable noise-emission input data plays a crucial role to obtain accurate results. In the directive 2002/49/EC [13], it was mentioned that suitable noise-emission data (input data) for industrial noise should be acquired from standards which are listed as ISO 8297 [40], ISO 3744 [41], and ISO 3746 [42]. ISO 3744 and ISO 3746 standards give information about the determination of sound power levels of noise sources. ISO 8297 standard is used for the determination of sound power levels of multisource industrial plants for the evaluation of sound pressure levels in the environment.

During industrial noise mapping, the sound insulation properties of the factory-building envelope are of great importance and the higher the sound insulation level, the less noise is transmitted noise from inside to outside. In the industrial noise calculation process, sound insulation properties of building envelop are considered, material sound insulation properties are used to calculate noise transmission which occurs inside of the production units, and outdoor noise propagation is analyzed according to building envelope sound insulation level. ISO 10140-2 [43] defines the sound reduction index and the sound reduction index is evaluated using Eq. 18. The measurements are carried out in laboratory test facilities in which sound transmission via flanking paths is prevented. Due to the existence of flanking transmissions, the results of measurements made in accordance with ISO 10140-2 standard do not apply directly to the field situation without accounting for other factors. In situ measurements, ISO 16283 1:2014 standard [44] is used to obtain sound insulation level and clarifies with a standardized level difference $\left(\mathrm{D}_{\mathrm{nT}}\right)$. The standardized level difference in which is standardized to a reference value of the reverberation time in receiving room is given in Eq. 19. ISO 16283-3:2016 standard [45] is used in situ measurements to analyze the sound insulation level of the façade. According to the ISO 16283-3:2016 standard [45], the façade's sound insulation index can be acquired by the road traffic method, which uses the noise produced by vehicle traffic passing in front of the building as the sound source. In ISO 16283-3:2016 standard, the standardized level difference $\left(\mathrm{D}_{2 \mathrm{~m}, \mathrm{nT}}\right)$ is used to measure the façade sound insulation level when the sound source is vehicle traffic and the external microphone is positioned $2 \mathrm{~m}$ from the measured surface. 
Standardized level difference $\left(D_{2 \mathrm{~m}, \mathrm{nT}}\right)$ is shown in Eq. 20. The ISO 717-1:2013 standard [46], which provides a weighted value for the insulation indices, presents a single index for sound insulation related to the ISO 10140-2 [43], ISO 16283-1 [44], and ISO 16283-3 [45] standards. Weighted results such as the weighted sound reduction index $\left(R_{w}\right)$ and the weighted standardized level difference $\left(\mathrm{D}_{\mathrm{nT}, \mathrm{w}}\right.$ and $\left.\mathrm{D}_{2 \mathrm{~m}, \mathrm{nT} \text {, w }}\right)$ are acquired in accordance with the ISO 717-1:2013 standard.

$\mathrm{R}=\left(L_{1}-L_{2}\right)+10 \lg \left(\frac{S}{A}\right)(\mathrm{dB})$

$\mathrm{L}_{1}$ The sound pressure level in the source room, in decibels

$\mathrm{L}_{2}$ The sound pressure level in the receiving room, in decibels

S The area of the free test opening in which the test element is installed, in square meters

A The equivalent sound absorption area in the receiving room, in square meters

$D_{n T}=\left(L_{1}-L_{2}\right)+10 \lg \left(\frac{T}{T_{0}}\right)(\mathrm{dB})$

$\mathrm{L}_{1}$ The sound pressure level at the acoustic emission site (dB)

$\mathrm{L}_{2}$ The sound pressure level in the receiving room $(\mathrm{dB})$

$\mathrm{T}$ The reverberation time of the receiving room (s)

$\mathrm{T}_{0} \quad$ The reverberation time of reference $\left(\mathrm{T}_{0}=0.5 \mathrm{~s}\right)$

$D_{2 m, n T}=\left(L_{1,2 \mathrm{~m}}-L_{2}\right)+10 \lg \left(\frac{T}{T_{0}}\right)(\mathrm{dB})$

$\mathrm{L}_{1}$, The sound pressure level measured outside the

$2 \mathrm{~m} \quad$ building with the microphone placed 2 meters from the measured surface $(\mathrm{dB})$

$\mathrm{L}_{2} \quad$ The sound pressure level in the receiving room $(\mathrm{dB})$

$\mathrm{T}$ The reverberation time of the receiving room (s)

$\mathrm{T}_{0} \quad$ The reverberation time of reference $\left(\mathrm{T}_{0}=0.5 \mathrm{~s}\right)$

\section{Preparing Industrial Noise Maps with Computer Modeling}

Industrial noise map calculations are generally performed with numerical simulations in the computer environment. Analyses are carried out in line with numerical simulations in the process of strategic noise mapping and action plans. In the literature, various noise mapping software are used in noise mapping simulations and it is observed that the most widely used noise mapping programs are SoundPLAN $[12,14,17,18,23$, 25, 47-50], CadnaA [15, 19-21, 51, 52], and Predictor [16, $36,53]$. In the research of Butorina et al. [12], SoundPLAN noise mapping software was used to analyze noise level, increasing the efficiency of the noise protection design process was carried out with the application of building information modeling (BIM). In the research, the development of the building information model was obtained using the data exchange between SoundPLAN, AutoCAD 3D, or Revit and Navisworks. In the research of Lokhande et al. [53], noise level analyses were performed surrounding mining and industrial areas of Keonjhar, and noise maps are prepared using Predictor LimA Software and other GIS tools. In the study of Jung et al. [52], it was stated that noise maps were prepared with CadnaA software that is widely used for environmental impact assessments.

Using numerical analysis methods other than noise mapping in noise analysis is useful in explaining many parameters that can be effective during the propagation of sound. Yuan et al. [54] stated that due to the various complex factors affecting noise in urban areas, the pathways linking built environment characteristics and the noise level have not been adequately addressed in the literature. In the research of Yuan et al. [54], it was aimed to examine the relationships of urban built environment and noise, using Pearson correlations and multiple linear regressions. In the research of Zhang et al. [55], it was researched multisource a noise emission and developed a model to predict noise level, and noise propagation simulator was used to estimate the noise levels at measurement locations under different settings of noise sources in the space. Computer models can be useful in determining the indoor noise level of multi-source industrial buildings.

Buildings, topography, roads, or other important data must be modeled and defined to simulation software in the noise mapping process. Butorina et al. [12] mentioned that the most effective way to determine noise protection measures is to use specialized software. In the SoundPLAN modeling process of this research, information about heights and elevation lines from Geo-Information Systems (as Autocad dxf file types) was imported into SoundPLAN, creation of a digital ground model which consists of information on the building heights and elevations was established, and entering of parameters of noise sources and buildings in SoundPLAN were identified according to field information. In the research of Bozkurt and Demirkale [7], a similar methodology was utilized. Attenuations, which can be listed as geometrical divergence $\left(\mathrm{A}_{\text {div }}\right)$, atmospheric absorption $\left(\mathrm{A}_{\mathrm{atm}}\right)$, ground effect $\left(\mathrm{A}_{\mathrm{gr}}\right)$, barrier $\left(A_{\text {bar }}\right)$, and other effects $\left(A_{\text {misc }}\right)$, were clarified in ISO 9613-2 standard [38]. In the software, the noise modeling process, meteorological data (humidity and temperature), ground properties (hard, porous, or mix ground), or other important data (barrier, reflections, vegetation, etc.) should be carefully defined to calculate attenuations and obtain accurate 
results. Besides, it is required to define the meteorological correction $\left(\mathrm{C}_{\mathrm{met}}\right)$ which is related to long-term local meteorological statistics.

Defining factory buildings is one of the most important steps in the industrial noise mapping process. First of all, the type of industrial buildings should be determined and indoor noise levels should be defined. The building type of industrial units can be selected according to field observations and production noise type can be determined from the simulation program database. Through performing measurements according to ISO 3744 [41] and ISO 3746 [42] standards, the sound power level of the industrial units can be determined in the noise mapping software. The production performance of industry units can change according to hours (day time, evening time, and night time, etc.). Hence, the production performance of industry units based on related time intervals should be determined in the noise modeling software. In the research of Bozkurt and Demirkale [7], based on field research, an internal sound source type was defined for every single industrial unit and industrial unit properties were detailed according to the internal sound source, which is standardized by SoundPLAN version 6.5 software. Moreover, industrial units working performance related to hours was defined according to information provided by industrial site staff and supported with field observations. The sound insulation properties of the factory-building envelope are an important issue to analyze outdoor noise propagation. When the insulation level of factory buildings increases, environmental noise related to industry decreases. For these reasons, it can be necessary to define noise data of industrial units and industrial units' sound insulation properties in the noise modeling program. Butorina et al. [12] stated in their research that building information modeling was used to identify industrial building. In the study, industrial building information, which is related to building floors, noise source, and their power levels, and material sound insulation properties were entered into models. In the research of Bozkurt and Demirkale [7], building envelope materials related to industrial units are defined (such as the wall, the window, the roof, the door, etc.), noise calculation was performed according to sound insulation level, and different working scenarios of industrial units were taken into consideration. In this research, four different working scenarios, which are related to the different opening of the doors of the industrial buildings, were analyzed and industrial noise maps were prepared according to industrial building envelope sound insulation properties.

In cases where there is no information about the industrial noise sources, it is important to determine what method should be followed. It should be kept in mind that as the level of uncertainty increases, the margin of error in noise calculations will increase. In the European Commission Working Group Assessment of Exposure to Noise (WG-AEN) document [56], it was clarified different methodologies exist when sound power levels of industrial sources are unknown. The comparison of the different methods when sound power levels of industrial sources are unknown were given in Table 2. In Table 2 methods, it is understood that the most accurate result is obtained when the ISO 8297 standard is used. However, it is seen that the method, which the ISO 8297 standard is used, is expensive and sophisticated compared to the methods given in Table 2. Using the following default values has the lowest accuracy in Table 2. Ports can be located near industrial noise sources and may contain industrial noise sources. For this reason, information about the ports was given in Table 2 . Fredianelli et al. [57] mentioned that noise sources inside port areas can be divided into several different categories which can be listed as road sources, railway sources, ship sources, port sources, and industrial sources. In port areas, the performance levels of the activities significantly affect the noise levels. The decrease in the activity levels in the ports can contribute to the decrease in the noise levels. Čurović et al. [58] stated in their research that shipping and industrial activities changed in the COVID-19 period and the $\mathrm{L}_{\mathrm{den}}$ period was analyzed due to the change of the shipping and industrial activities in the COVID-19 period. According to analyses, it was mentioned that compared to the historical period, the number of people exposed to noise levels above $55 \mathrm{dBA}$ decreased by $20 \%$ in the COVID-19 period [58]. In the research of Basu et al. [59], Dublin city noise pollution was analyzed and sound levels were investigated before and after the lockdown imposed as a result of the COVID-19 pandemic. Changes in noise pollution due to the COVID-19 lockdown were researched by using measured hourly data from noise monitoring stations between January and May 2020. It was observed in this research [59] that a significant decrease in hourly average equivalent sound and hourly minimum sound levels was acquired at all stations during the lockdown period. As a result, industrial activities can be affected by social events, pandemics, and economic crises. In the noise modeling process, industrial activity levels should be considered to obtain accurate results.

Strategic noise maps are generally carried out according to an assessment height of $4 \mathrm{~m}$ which is defined in the Environmental Noise Directive (2002/49/EC) [13]. The grid system of the noise maps prepared by computer simulation is an important parameter for the clarity of the noise map. Murphy et al. [4] stated in their study that the generation of noise maps involves the calculation of the noise levels of the respective sources to the receiver points along a systematic grid located on the analyzed area. In the noise modeling process, the smaller the grid spacing, the more detailed calculations in the noise map preparing process are acquired. Butorina et al. [12] stated that the calculated area is divided on a grid to calculate noise propagation in preparing noise maps and the noise map grid system can be identified as $5 \mathrm{~m}$ and $10 \mathrm{~m}$ not more than $30 \mathrm{~m}$. In the research of Bozkurt and 
Table 2 The comparison of the different methods when sound power levels of industrial sources are unknown [56]

\begin{tabular}{|c|c|c|c|c|c|c|}
\hline \multicolumn{4}{|l|}{ Method } & Complexity & Accuracy & Cost \\
\hline \multicolumn{4}{|c|}{ Obtain sound power levels from source operator } & 3 & 3 & 3 \\
\hline \multicolumn{4}{|c|}{ Determine sound power levels using ISO 8297} & 4 & 4 & 4 \\
\hline \multicolumn{4}{|c|}{ Use input data contained in an EIA (Environmental Impact Assessment) } & 2 & 2 & 2 \\
\hline \multicolumn{4}{|c|}{ Use nationally defined default source sound power levels } & 1 & 2 & 1 \\
\hline \multicolumn{4}{|c|}{ Use nationally defined maximum permissible sound power levels per unit of surface area } & 1 & 2 & 1 \\
\hline \multicolumn{4}{|c|}{ If Directive 2000/14/EC provides limiting values for source under consideration, use these values } & 2 & 2 & 2 \\
\hline \multicolumn{4}{|l|}{ Use public databases } & 3 & 3 & 2 \\
\hline \multirow[t]{2}{*}{$\begin{array}{l}\text { Use the following default values: } \\
\text { Type of industry }\end{array}$} & \multicolumn{3}{|c|}{ Default value for $\mathrm{L}_{\mathrm{w}} "\left(/ \mathrm{m}^{2}\right)$} & 1 & 1 & 1 \\
\hline & day & evening & night & & & \\
\hline Area with heavy industries & $65 \mathrm{dBA}$ & $65 \mathrm{dBA}$ & $65 \mathrm{dBA}$ & & & \\
\hline Area with light industries & $60 \mathrm{dBA}$ & $60 \mathrm{dBA}$ & $60 \mathrm{dBA}$ & & & \\
\hline Area with commercial uses & $60 \mathrm{dBA}$ & $60 \mathrm{dBA}$ & $45 \mathrm{dBA}$ & & & \\
\hline Ports & $65 \mathrm{dBA}$ & $65 \mathrm{dBA}$ & $65 \mathrm{dBA}$ & & & \\
\hline
\end{tabular}

Coding numbers ( 1 to 4 ) increase when the level increase. 4 means the maximum level and 1 means minimum level

For complexity, 1 is simple and 4 is sophisticated

For accuracy, 1 is low and 4 is high

For cost, 1 is inexpensive and 4 is expensive

Demirkale [7], the noise map grid system was determined in the noise mapping process and the industrial noise maps were prepared with a grid width of $10 \mathrm{~m}$.

It is required to obtain population information for the region whose noise map is prepared and define it to the model. Population data are obtained and entered into the software. The number of people exposed to excessive noise is determined in line with population data. In general, the steps considered in the preparation of industrial noise maps in the computer environment are given in Fig. 2. In the literature, it is seen that besides industrial activities, traffic noise can also be effective and traffic noise can be analyzed together with industrial noise. This situation was observed in the researches of Morel et al. [60], Marquis-Favre and Morel [61], and Bernardini et al. [49]. In the modeling process, both industrial noise and traffic noise should be considered to obtain accurate results.

The current situation is analyzed according to the noise mapping results and the problems in the current situation are determined. After current situation analyses, the determination of planning decisions, which is related to the improvement of environmental quality based on industrial noise map results, are performed. In urban planning decisions, the suggestion of a protective green zone between residential and industrial areas, the suggestion of barrier design, the suggestion of the removal of noisy areas in the settlements can be offered to decrease the excessive noise level. In "The Improvement of Environmental Quality" section, the improvement of environmental quality is explained in detail.

\section{Noise Measurements and Monitoring System}

Noise measurement should be performed in accordance with ISO 1996-1 [62] and ISO 1996-2 [63] standards. Calibration of noise measurement devices is of great importance in terms of the accuracy of the measurement results. Noise measurements are usually performed on grade at 1.5 to $4 \mathrm{~m}$ above ground. The duration of the measurements is also one of the important analysis parameters. In the industrial noise mapping research of Bozkurt and Demirkale [7], industrial noise measurements were carried out for $5 \mathrm{~min}$ in sixteen different measurement points and receivers were located at 1.5 $\mathrm{m}$ height from the ground. In the research of Farooqi et al. [3], measurements were carried out in the industrial area with the sound level meter device and the measurement results were evaluated together with the survey studies. Rosmala et al. [64] prepared acoustic noise maps on various locations in Surabaya, and in the noise measurement process, the measurement was done in five minutes at each point. Chi et al. [65] stated that noise map data were collected by noise measurement in Vietnam (Can Tho city), noise measurements were performed in the gridline which is $10 \mathrm{~m} \times 10$ $\mathrm{m}$, noise measurement period is $10 \mathrm{~min}$, and noise map was established according to measurement results. Farooqi et al. [3] mentioned that the textile industry area is located in mixed areas where the industrial, commercial, and residential areas exist in Pakistan. It 
was stated that the maximum sound pressure level (Lmax) was measured $102 \mathrm{dBA}$ inside the production unit, $94 \mathrm{dBA}$ outside the production unit, and $99 \mathrm{dBA}$ outside the industry in the afternoon.

Noise mapping simulations should be validated by noise measurements. Moreover, modeling process and measurement uncertainties are required to clarify. In the European Commission Working Group - Assessment of Exposure to Noise (WG-AEN) document [56], modeling process input data was identified, information about uncertainties about noise modeling was given, and level differences which may occur depending on the modeling process were defined. In the research of the Zannin and Sant'Ana [36], noise maps were prepared using the Predictor BK 7810 version 6.0 software, and the model was calibrated using as reference the recommendations of WG-AEN [56]. Gómez et al. [47] researched the use of noise measurements when noise mapping models are intended to be validated and an assessment of the noise mapping process was carried out to analyze uncertainties using SoundPLAN software. Butorina et al. [50] stated that measurements of noise levels in the urban area were used to calibrate the SoundPLAN model in the preparation of the noise map of St. Petersburg. In the research of Gómez et al. [47], it was mentioned that the requirement of noise measurement uncertainties needs to clarify (usually assumed as \pm 3 $\mathrm{dBA}$ ) and it was defined that the inaccuracy of the georeferencing process affects the noise map results negatively.

Noise monitoring systems are used frequently and provide long-term measurement results. Alam et al. [66] mentioned that the noise monitoring systems were used for the development of 2D and 3D noise maps. 3D noise maps provide to obtain reliable results of the noise level around the source of noise in X, Y, and Z directions. Kalawapudi et al. [67] stated in their study that measurements were made using the noise

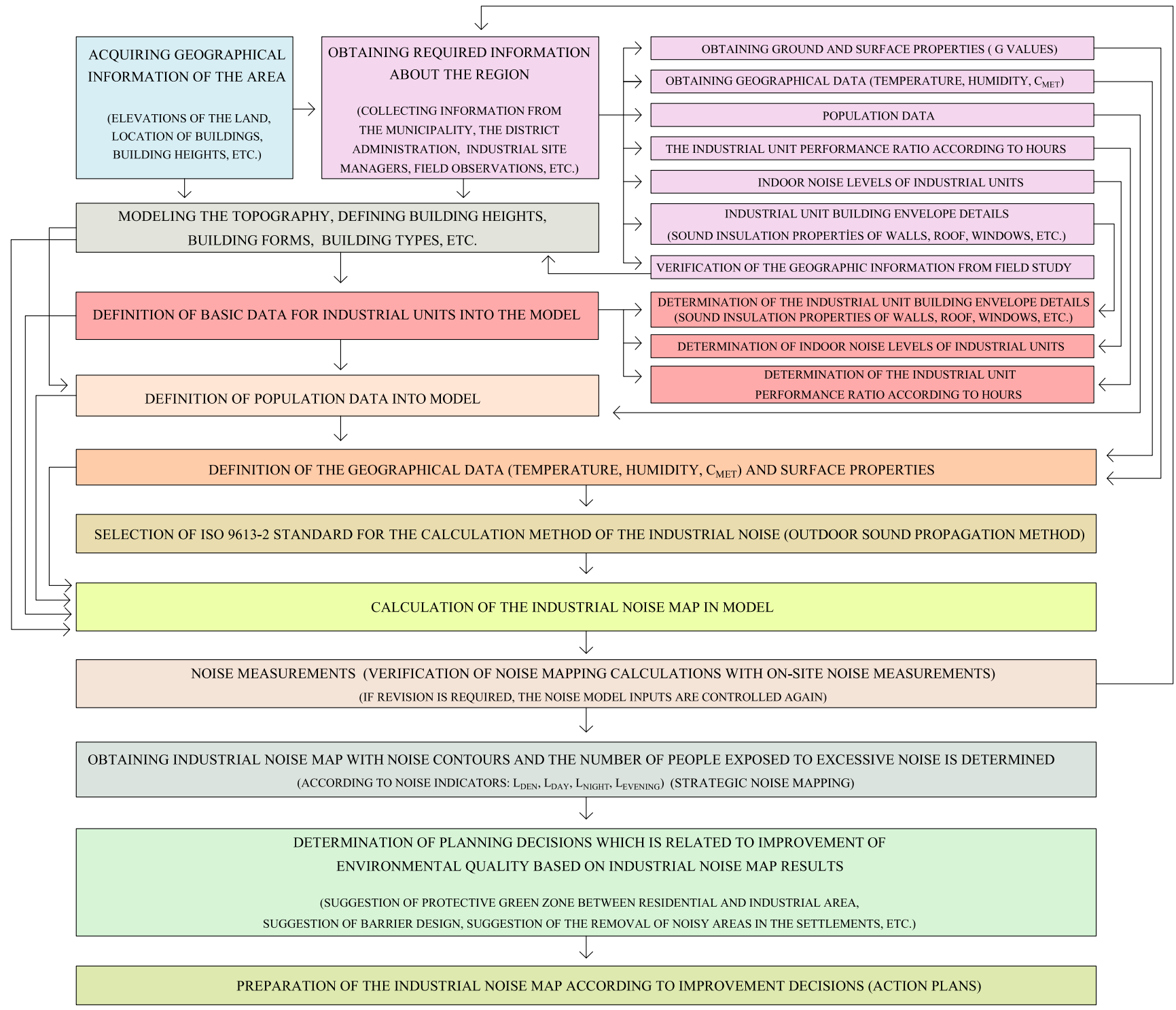

Fig. 2 The process of the industrial noise mapping in the simulation software 
monitoring system integrated with GPS (Global Positioning System) and stated that the noise levels of the whole model can be predicted with a limited number of measurements. Paschalidou et al. [68] investigated noise pollution in an extended motorway located in Greece. Researchers used both computer modeling program and 3-year monitoring systems in the strategic noise mapping process, the monitoring system measurements were done at a height of 4 meters above ground, and noise measurements per year were carried out between 2013 and 2015. The authors underlined the importance of monitoring systems in their study. The monitoring system helped to authors to evaluate noise levels and to perform the necessary calibration of the model for strategic noise mapping. Bulkin et al.[69] investigated noise situation in an urbanized area in the presence of vehicular and industrial noise. In their study, utilizing the monitoring system, both maximum and average values of sound pressure were analyzed to satisfy auditory comfort conditions.

Bite and Sillo [70] gave information about long-term noise monitoring and dynamic noise mapping and explained the case study, which was carried out in Dubai. The web-based applications which help to access data more quickly were developed by authors. In the future, web-based applications based on noise monitoring will be widely used and will be able to provide instant information about industrial noise. The establishment of web-based and real-time noise measurement monitoring systems is also targeted in studies in different countries. For example, Alsina-Pagès et al. [6] stated for the future goals to enable the real-time monitoring of the acoustic environment of the country, the development of real-time operation with a network of acoustic sensors deployed in Andorra and Escaldes-Engordany was aimed. Noise monitoring systems can detail the changes in noise levels over the years and contribute to the determination of urban growth policies. Xu et al. [71] mentioned that the noise monitoring data from 111 cities in China from 1991 to 2017 was used to analyze the relationship between noise pollution and economic development. In the study, it was clarified that the development of the tertiary industry will increase noise pollution. Noise monitoring systems can help planners and policymakers to determine long-term development plans.

Since smartphones are widely used today, the use of smartphones in noise measurement increases the total number of measurement data in noise mapping studies. Hence, it is observed that the use of smartphones in noise measurement can be recommended in recent studies. For example, Picaut et al. [72] mentioned the crowdsourcing approach for producing noise maps using a smartphone can be beneficial, and physical data collection can be performed without territorial limits. In the research of Lee et al. [73], crowdsourcing of environmental noise data was obtained using smartphones and noise maps were prepared. Due to the different types of smartphones' existence, researchers suggested calibrated smartphone usage, and researchers claimed the viability of using calibrated smartphones for the monitoring of environmental noise. Marques and Pitarma [74] informed about noise mapping through mobile crowdsourcing and the benefits of smartphone usage in the noise mapping process were clarified. Especially Marques and Pitarma [74] stated in the study that crowdsourcing techniques applied to environmental noise monitoring provide creating reliable noise maps at a low cost. In the literature, it can be observed that there are also negative aspects of using smartphones in noise mapping. Liu et al. [75] summarized the criteria for the design of crowdsensing systems and mobile applications about noise mapping in smart cities and mentions smartphone crowdsensing systems' advantages and disadvantages in the noise assessment. About smartphone crowdsensing systems, six technical challenges, which can be listed as noise measurement accuracy, positioning accuracy, energy consumption, privacy preservation, and fine-grained mapping, were clarified.

\section{The Improvement of Environmental Quality}

Improvement decisions are performed according to the noise mapping results and the action plans specified in the noise directive 2002/49/EC [13] are determined to enhance the environmental quality. Through the action plans, it is aimed to reduce the number of people exposed to excessive noise. To improve environmental noise, the improvements at the building scale and the improvements at the urban scale should be considered separately in industrial noise analysis. For this reason, "The improvement of environmental quality" section is examined under two different subtitles.

- The improvements at the building scale

- The improvements at the urban scale

\section{The Improvements at the Building Scale}

In industrial noise control, successful results can be obtained on the urban scale if the sound generated in the industrial building can be reduced by intervening at the building scale. In this context, the sound insulation level of the building envelope of the production building has great importance. Bozkurt and Demirkale [7] mentioned in their research that depending on seasonal temperatures, industrial units can operate by opening their doors at different rates in order to reduce indoor temperatures. Analyses were made according to the different door opening ratios and it was stated that the number of people exposed to excessive noise in the residential area may increase due to the increase in the door opening ratio. 
Bozkurt and Demirkale [7] demonstrated that the sound insulation level of the industrial unit-building envelope is an important parameter. Ensuring the door and window sealing in terms of sound insulation reduces transmitted sound energy from interior to exterior. It is necessary to cool the interior of the industrial units with the central ventilation system in the hot season and in this case, doors and windows should not be opened for cooling the interior.

In industrial building, increasing indoor surfaces sound absorption properties can reduce indoor noise levels. Decreasing indoor noise level not only ensures rehabilitation working conditions of workers but also can decrease the excessive outdoor noise level. In their research, Butorina et al. [12] suggested using baffles (as sound absorptive materials) to reduce the interior noise level in an industrial building; noise levels with sound absorption improvements were calculated and the noise level was decreased by $2-14 \mathrm{dBA}$ at the workplaces. Fan et al. [76] analyzed the noise of transformers in the substation and it was aimed to reduce noise problem through experimental investigations on the vibration. In this research, the sound-absorbing structure, acoustic insulation structure, and vibration isolators were used to decrease noise. It was shown that by using vibration isolators, the transmission of noise can be reduced and the insulation level of residential areas can be increased. Mendonça and Leite [27] stated that using a vibration damper below the press machine can decrease noise transmission. Prabu et al. [77] performed research in the glass manufacturing industry to control industrial noise. It was stated that some of the usual techniques for control of sound in the transmission path are mufflers, vibration insolation, break mechanical paths, increasing the transmission paths, use of sound absorptive materials, and construction of heavy airtight enclosures. In the research of Moravec et al. [51], noise reduction from a wastewater treatment plant was explained. Noise reduction in wastewater plants was achieved by means of the replacement of ventilation grilles with acoustic blinds and the providing the acoustic insulation of air distribution pipes.

In general, it is recommended to use earplugs to protect the health of workers where industrial noise is active. Tomoze1 et al. [29] analyzed industrial building interior noise levels and stated that to protect workers from noise, earplugs can be used in areas where noise levels of about $80 \mathrm{~dB}$ are recorded. Prabu et al. [77] stated that an ear protector is used to reduce the effect of ambient sound on the auditory system and mentioned two different types of ear protectors, which are earplugs and earmuffs. Lim et al. [30] stated that workers were used earplugs in the rubber factory but it is not only enough to provide requirements. Also, barrier usage was suggested to improve the interior of the rubber factory environment quality.

\section{The Improvements at the Urban Scale}

It is essential to design urban planning by taking noise measures to provide auditory comfort conditions. In this context, when the noise reduction measures are concerned at the first design stage, healthier living spaces can be obtained. Bozkurt and Demirkale [7] indicated that the location of the industrial areas must be designed properly in terms of noise control and public health in the city planning process. Morillas et al. [78] investigated the topic of noise pollution and urban planning and stated that good relationships between urban planning and different factors such as urban density, urban morphology, urban land use, street distribution, street environment, and green spaces exist. Morillas et al. [78] mentioned that several studies have been performed to connect noise levels with urban planning and urban morphology. Also, Morillas et al.[78] explained that new areas may be more comfortable than traditional areas when noise levels are taken into consideration in the city design process by those responsible for the new urban design. Yuan et al. [54] stated that high-density and high-rise building areas can contribute to noise pollution and because of this reason, controlling building density is an important parameter in noise control. Kalawapudi et al. [67] indicated that unplanned city areas negatively affect silence zones. The vehicle road, which provides access to industrial zones, is one of the important parameters in urban planning. In the research of Lokhande et al. [53], it was stated for surrounding mining and industrial areas of Keonjhar, the present noise level is at $60 \%$ of the locations in silence and residential zone exposed to high noise levels than the maximum required value determined by Indian central pollution control board and it was proposed to construct alternative transportation routes to improve the noise level.

To prevent industrial noise transmission from industrial areas to settlements, noisy industrial areas should be located away from residential areas as much as possible. In Eq. 7 ( $\mathrm{A}_{\text {div }}$, attenuation due to geometrical divergence), it is understood that when the distance from the source to receiver increases, attenuation also increases. For this reason, industrial areas should be designed as a different zone away from living spaces and should be located as far away from living spaces as possible. Separating living spaces and industrial areas and increasing the distance between them is a good approach in terms of noise control. In addition, the design of a protective green zone between residential and industrial areas can be useful to reduce noise pollution (Fig. 3a). Kotzen and English [79] indicated in their books that it may be beneficial to increase the distance of the noise sources from the receivers and design green areas between them. Yuan et al. [54] mentioned that forest areas and grasslands can reduce noise but forest areas can be more effective in reducing noise than grasslands. Margaritis and Kang [80] stated that at the macro-scale, the green space pattern affects not only the structure of the city 

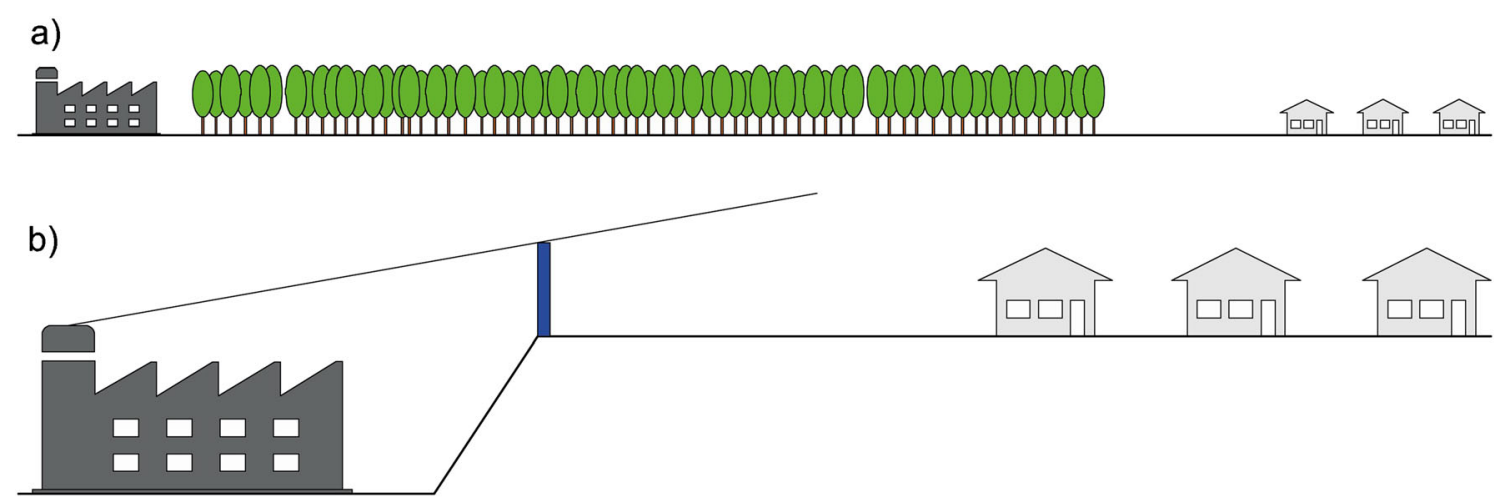

c)

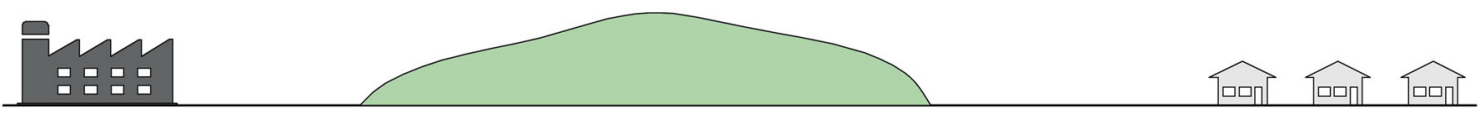

d)

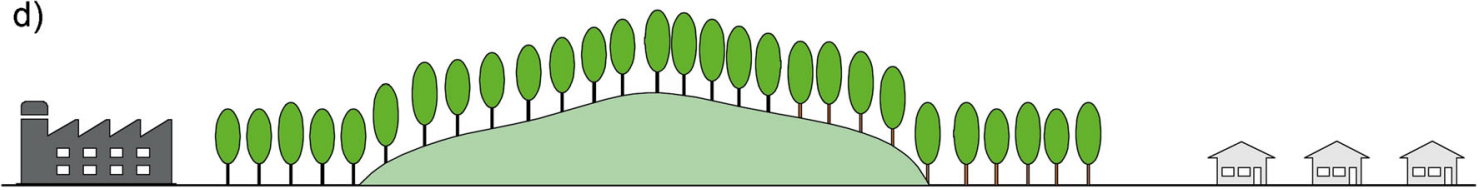

Fig. 3 The improvement strategies of industrial noise control: a increasing distance and designing protective green zones between industrial areas and settlements, $\mathbf{b}$ designing the industrial zone at the lower elevation according to the residential area and barrier design, $\mathbf{c}$ earth mounds barrier type, $\mathbf{c}$ earth mounds barrier type extended planting but also the noise levels in combination with the rest of the morphological parameters. Also, Margaritis and Kang [81] performed research about the relationship between green space-related morphology and noise pollution, and green spaces' effects on noise pollution at the urban scale were investigated. In the research, it was determined that lower noise levels can possibly be obtained in cities with a higher extent of porosity and green space coverage.

Barrier design is one of the common methods used to reduce noise levels. Butorina et al. [50] determined that the most spread measures to decrease noise are the installation of noise barriers and usage of sealed glazing system that has sound insulation properties. In Eqs. 10 and $11\left(\mathrm{~A}_{\mathrm{bar}}\right.$, attenuation due to a barrier), it is observed that when the barrier high and barrier length increases, the barrier attenuation also increases in general. Jaramillo and Steel [82] explained barrier arrangements in their book and stated that increasing the site settlement level can also reduce the required barrier height (Fig. 3b). Increasing the site settlements level is very effective to control noise pollution when there is a noise source on the roofs of industrial buildings (Fig. 3b). Designing the industrial zone at the lower elevation according to the residential area provides to decrease in barrier height (Fig. 3b). A very high single barrier design may not be preferred when there is no level difference between living spaces and industrial areas. In these cases, it may be desired to provide a barrier system by creating earth mounds (Fig. 3c). Kotzen and English [79] indicated in their books that earth mounds barrier type may have a natural appearance and may not appear to be noise barriers at all. Besides, Kotzen and English [79] stated earth mounds barrier type may be less costly to maintain and usually have an unlimited life span. When industrial noise sources exist on the factory roof, the noise barrier system should have enough height. In such cases, the earth mounds barrier system becomes too high. Hence, for his reason, the earth mounds barrier system may not have a natural appearance due to the height properties (Fig. 3c). Kotzen and English [79] stated that earth mounds barrier type can be designed with planting or without planting and extended planting area can prevent to perceive the mound form (Fig. 3d). Afforestation of the top of the earth mound and the edges of the earth mound contribute to achieving the natural view (Fig. 3d).

In the research of Bozkurt and Demirkale [7], a sound barrier design near the industrial site was suggested to decrease the number of people affected by noise, and through noise barrier suggestion, the number of people affected by noise was decreased considerably. Paschalidou et al. [83] stated in their research that it was suggested to build noise barriers approximately $2700 \mathrm{~m}$ long for the protection of 25 school complexes and 2 residential areas. In the study of Jung et al. [52], barrier optimization was analyzed and it was stated that noise barrier optimization would help to prevent people from construction noise exposure. Zannin et al. [48] researched the application of artificial neural networks for noise barrier optimization, and through the application of simulated noise barriers, it was expressed that noise levels can be decreased to legally acceptable levels. According to the results obtained from the simulations, it was shown that the absorption coefficient strongly affects noise 
attenuation provided by noise barriers. Also, Zannin et al. [48] indicated that transmission loss of an acoustic barrier is more affected by the absorption coefficient of the barrier than by its height, while the acoustic shadow is more affected by the height of the barrier than by its absorption coefficient. In the literature, it may be seen that barrier systems are designed not only to reduce noise pollution but also to produce energy from solar energy. Kanellis et al. [84] researched the noise barriers which is used in both noise reduction and energy production. Bognár et al. [85] showed that noise barrier systems can be used to not only decrease noise levels but also produce energy from the sun.

In the literature, too many material-based researches are carried out to sort out noise problems in cities. Licitra and Vogiatzis [86] stated that the scientific community is moving towards new acoustic solutions that also look at the green economy, recycling, new pavements, and sustainable vehicles and tires. In the scope of this, the acoustic properties of barrier system and road surface properties have great importance to reduce noise pollution, and material-based researches are carried out frequently in the literature. Barrier system sound absorption properties and transmission loss properties can be enhanced in a line with the change of thickness of barrier, surface type, mixture type. Kotzen and English [79] indicated that covering the barrier surface with a sound absorption material reduces the strength of the reflected ray. Accordingly, excessive noise levels in urban areas can be decreased by means of the increase of the sound absorption of barrier surfaces. Mortar-based sound barrier systems are usually used in urban areas. Hence, in the studies that are seen in the literature, sound absorption properties based on mortar mixture type are usually investigated to improve material acoustic properties. Maheswaran et al. [33] analyzed the power press industry noise map and showed that indicate the highest levels of noise was ranging from 80 to 110 decibels. To reduce noise due to the press industry, Maheswaran et al. [33] suggested to use barrier which produced with gypsum; three different mixture which the quantity of coir varies from $1 \mathrm{~g}, 3 \mathrm{~g}$, and $5 \mathrm{~g}$ respectively were analyzed; transmission loss measurements are carried out according to ISO 10534-2:1998 [87] standard and the highest transmission loss was acquired from in the composite containing $5 \mathrm{~g}$ of coir. Gandoman and Kokabi [88] investigated sound barrier properties of sustainable waste rubber/ geopolymer concretes, and Gandoman and Kokabi indicated that waste rubber geopolymer concrete mixture type can provide to obtain higher sound transmission loss and better sound absorption compared to conventional concrete samples. Bozkurt and Demirkale [89-93] investigated mortar mixture types produced with a natural hydraulic lime binder (NHL $3.5)$ to increase the sound absorption of the plasters. In the first step of the research [89], mixture types, which are used in building restorations, were analyzed. In the second step of the research [90], it was offered new mortar mixture types produced with river sand aggregate type to increase sound absorption. In the third step of the research [91], the use of the lightweight aggregate in mortar mixtures was analyzed and it was suggested new mortar mixture types produced with pumice aggregate type to enhance sound absorption in the plaster layer. In the last step of the research [92], the use of perlite aggregate type as the lightweight aggregate in the mortar mixtures was investigated. As a result of researches, it was identified that decreasing the amount of binder ratio can increase the sound absorption coefficient [90], the use of very fine aggregate can decrease the sound absorption coefficient [90], and the use of polypropylene and flax fiber additive can enhance sound absorption at low frequencies [90-93]. Also, it was determined that the use of crumb rubber instead of aggregate can increase sound absorption significantly at low frequencies [90-93] and the use of lightweight aggregate type can be a good way to improve sound absorption coefficients $[91,92]$. In the research of Corredor-Bedoya et al.[94], Mohammed et al.[95], Pastor et al.[96], Medina et al.[97], Holmes and Browne [98], and Sukontasukkul [99], it was demonstrated that the use of crumb rubber in the place of aggregate can affect the sound absorption coefficient positively at certain frequencies.

The acoustic properties of road covers and pavements are one of the important parameters in the urban scale and new solutions related to road covers, which are generally used as asphalt covering and concrete covering, are researched to decrease noise pollution. In Eq. 9, it is demonstrated that when the $G$ value of the ground covering increases, also, the attenuation due to the ground effect $\left(\mathrm{A}_{\mathrm{gr}}\right)$ increases. The $\mathrm{G}$ value is related to the sound absorption coefficient, and as the $G$ value increases, the sound absorption coefficient generally increases. For this reason, as the sound absorption coefficient of road covering increases, the level of reduction due to ground attenuation increases, and this situation contributes to the reduction of noise pollution. In the research of $\mathrm{Chu}$ et al. [100], the sound absorption characteristics of porous asphalt pavement wearing course mix designs were investigated, and the effects of the mixture properties, which are the percent porosity of mixture and degree of clogging that occurred, were analyzed. It was shown in the research that the sound absorption coefficient can increase as the porosity increases and clogging of the pores in the mixtures can cause to decrease sound absorption coefficient significantly. Vaitkus et al. [101] investigated commonly used asphalt concrete (AC), stone mastic asphalt (SMA), porous asphalt (PA), and a concept of noise-reducing asphalt mixtures. In the research, the sound absorption coefficient for each asphalt mixture with optimal binder content was examined and it was showed that porous asphalt mixture type has the highest sound absorption coefficients in the frequency range from 500 to $2000 \mathrm{~Hz}$. Wang et al.[102] researched improvement of acoustic model and structural optimization design of porous asphalt concrete. In the study, it was depicted that mixture type air void ratio 
can enhance sound absorption and low-frequency sound absorption performance can be increased by means of the increasing pavement thickness. In the research of Chu et al. [103], sound absorption characteristics of pervious concrete were examined, pervious concrete and porous asphalt were compared, four porosity levels of pervious concrete and porous asphalt were investigated $(10 \%, 15 \%, 20 \%$, and $25 \%)$, and the effect of clogging was analyzed. In the study, it was found that in both pervious concrete and porous asphalt mixtures, the sound absorption performance reduced as the percentage of clogging increased, the increase of specimen thickness can enhance low-frequency sound absorption performance, and pervious concrete can demonstrate a better sound absorption capability than porous asphalt. Shen et al. [104] examined basic oxygen furnace slag for substitution of aggregate in porous asphalt mixture and researched the change of aggregate type used in asphalt coating. In the research, it was demonstrated that the use of basic oxygen furnace slag as aggregate in the asphalt layer can enhance sound absorption performance. In the study of Zhao et al. [105], porous sound-absorbing concrete slabs were investigated to reduce railway noise and different types of mixtures are prepared to achieve noise reduction. It was determined that the use of superfine aggregate type can decrease sound absorption, the use of lightweight aggregate type can improve sound absorption and the use of polypropylene fiber additive can enhance sound absorption. In the research of Oancea et al. [106], the sound absorption coefficient of sustainable concrete with different waste replacements are investigated, and five different types of sustainable concrete, which consist of polystyrene granules, polyethylene terephthalate granules, corn cob granules shredded sunflower stalk, and balls made of sheep wool, were analyzed. Oancea et al. [106] stated that each of the sustainable concrete has sound absorption coefficients higher than those of the conventional concrete and in the cities, and these types of materials can be used as a sustainable solution for both waste and noise problems.

It is seen that material-based researches improving acoustical properties are a very wide research subject and it is understood that too many different studies about material-based researches improving acoustical properties exist in the literature.

\section{Conclusion}

The noise pollution should be controlled to provide auditory comfort conditions and healthy living areas. In this research article, noise pollution, which is related to industrial activities, is detailed. First, the negative effects of excessive noise on human health and the types of noise sources encountered in industrial areas are explained. The importance of industrial noise mapping is expressed and evaluation methodologies are clarified. In the "The Strategic Noise Mapping Process Based on Industrial Noise" section, the strategic noise mapping process based on industrial noise is detailed; calculation methodology in industrial noise mapping, which is related to outdoor sound prorogation, is clarified; preparing industrial noise maps with computer modeling is explained; and noise measurements and monitoring systems are explained. As a result of the industrial noise mapping, existing excessive noise problems can be determined and improvement suggestions can be presented in this direction. As a result of the industrial noise mapping, it is understood that existing excessive noise problems can be determined and improvement suggestions can be presented in this direction. In "The Improvement of Environmental Quality" section, the methodologies about the improvement of environmental quality, which may be at the building scale or the urban scale, are defined in detail. The measures, which can be specified inside the building and at the noise source, are explained, and the suggestions, which can be considered at the city scale, are clarified.

In summary, the main measures, which should be considered at the building scale, are as follows:

- To increase the sound insulation level of the industrial building envelope,

- To increase the sound absorption level inside of the industrial building, and

- To control the noise level at the noise source.

The main measures, which should be considered at the urban scale, are mentioned below:

- Noise pollution should be considered as an important parameter in urban design and urban designs should be performed to include noise measures.

- The distance between the source and the receiver should be increased as much as possible. If it is possible, industrial zones should be designed in different areas, which are away from residential areas.

- The design of a protective green zone between residential and industrial areas is a good way to reduce noise pollution.

- The design of a noise barrier can decrease noise levels in the living spaces and design parameters should be considered.

- Material-based improvements (increasing sound absorption performance or sound transmission loss performance) can improve noise level at the urban scale.

Material-based researches improving acoustical properties can be investigated in many different ways and include a wide range of research areas. Different material-based researches improving acoustical properties are a very broad research subject in terms of literature research. It is estimated in future 
studies that this article can be useful for professionals working on noise mapping and academic researchers.

\section{Declarations}

Conflict of Interest The author declares that he has no conflict of interest.

Human and Animal Rights and Informed Consent This article does not contain any studies with human or animal subjects performed by any of the authors.

\section{References}

1. World Health Organization, (2018), Environmental Noise Guidelines for the European Region, ISBN 9789289053563

2. Özgüven, HN, (2008), Gürültü Kontrolü Endüstriyel ve Çevresel Gürültü, Turkey Acoustic Association publications, extended 2nd edition, ISBN: 978-605-89991-0-7

3. Farooqi ZUR, Sabir M, Latif J, Aslam Z, Ahmad HR, Ahmad I, et al. Assessment of noise pollution and its effects on human health in industrial hub of Pakistan. Environ Sci Pollut Res. 2020;27:2819-28. https://doi.org/10.1007/s11356-019-07105-7.

4. Murphy E, Faulkner JP, Douglas O. Current state-of-the-art and new directions in strategic environmental noise mapping. Curr Pollut Rep. 2020;6:54-64. https://doi.org/10.1007/s40726-02000141-9.

5. Arbaoui I, Hamou A, Abderrahim H, Tayeb A, Chellali MR. Intercomparison of noise pollution in Oran (Algeria) : urban and industrial areas. J Mater Environ Sci. 2018;9(1):1-10. https://doi. org/10.26872/jmes.2018.9.1.1

6. Alsina-Pagès RM, Vilella M, Pons M, Garcia Almazan R. Mapping the sound environment of Andorra and EscaldesEngordany by means of a 3D city model platform. Urban Sci. 2019;3:89. https://doi.org/10.3390/urbansci3030089.

7. Bozkurt TS, Demirkale SY. The field study and numerical simulation of industrial noise mapping. J Build Eng. January 2017;9: 60-75. https://doi.org/10.1016/j.jobe.2016.11.007.

8. Sheikh MS, Majeed S, Ali S. Noise induced hearing loss among industrial workers of south Punjab, Pakistan. Prof Med J. 2020;27(05):1022-6. https://doi.org/10.29309/TPMJ/2020.27.05. 4115.

9. Farooqi Z.I.R., Sabir M., Zeeshan N., Murtaza G., Hussain M.M., Ghani M.U., (September 9th 2020). Vehicular noise pollution: its environmental implications and strategic control, autonomous vehicle and smart traffic, Ersoy S. and Waqar T., IntechOpen, DOI: https://doi.org/10.5772/intechopen.85707. Available from: https:/www.intechopen.com/books/autonomous-vehicle-andsmart-traffic/vehicular-noise-pollution-its-environmentalimplications-and-strategic-control

10. Basner M, McGuire S. WHO Environmental Noise Guidelines for the European Region: a systematic review on environmental noise and effects on sleep. Int J Environ Res Public Health. 2018;15(3): 519. https://doi.org/10.3390/ijerph15030519.

11. Lercher P. Combined transportation noise exposure in residential areas. Encycl Environ Health, 2nd Edition. 2019;1:695-712. https://doi.org/10.1016/B978-0-12-409548-9.11280-1.

12. Butorina M, Drozdova L, Kuklin D, Sharkov A, Aref'ev K, Sopozhnikov S, et al. Implementation of noise data into building information model (BIM) to reduce noise in the environment and at workplace. In: In IOP Conference Series: Earth and
Environmental Science. 337th ed. Bristol: IOP Publishing Ltd; 2019. p. 012083. https://doi.org/10.1088/1755-1315/337/1/ 012083. Retrieved from https://iopscience.iop.org/article/10. 1088/1755-1315/337/1/012083.

13. Union, E. Directive 2002/49/EC of the European Parliament and the Council of 25 June 2002 relating to the assessment and management of environmental noise. Off J Eur Communities. 2002;L 189:12-25.

14. Seong JC, Park TH, Ko JH, Chang SI, Kim M, Holt JB, et al. Modeling of road traffic noise and estimated human exposure in Fulton County, Georgia, USA. Environ Int. 2011;37(8):1336-41. https://doi.org/10.1016/j.envint.2011.05.019.

15. Suárez E, Barros JL. Traffic noise mapping of the city of Santiago de Chile. Sci Total Environ. 2014;466-467:539-46. https://doi. org/10.1016/j.scitotenv.2013.07.013.

16. Fiedler PEK, Zannin PHT. Evaluation of noise pollution in urban traffic hubs-noise maps and measurements. Environ Impact Assess Rev. 2015;51:1-9. https://doi.org/10.1016/j.eiar.2014.09. 014.

17. Bunn F, Zannin PHT. Assessment of railway noise in an urban setting. Appl Acoust. 2016;104:16-23. https://doi.org/10.1016/j. apacoust.2015.10.025.

18. Thacher JD, Poulsen AH, Raaschou-Nielsen O, Jensen A, Hillig $\mathrm{K}$, Roswall N, et al. High-resolution assessment of road traffic noise exposure in Denmark. Environ Res. 2020;182:109051. https://doi.org/10.1016/j.envres.2019.109051.

19. Zhao W, Liu E, Poh HJ, Wang B, Gao S, Png CE, et al. 3D traffic noise mapping using unstructured surface mesh representation of buildings and roads. Appl Acoust. 2017;127:297-304. https://doi. org/10.1016/j.apacoust.2017.06.025.

20. Morillas JMB, González DM, Escobar VG, Gozalo GR, VílchezGómez R. A proposal for producing calculated noise mapping defining the sound power levels of roads by street stratification. Environ Pollut. 2021;270:116080. https://doi.org/10.1016/j. envpol.2020.116080.

21. Wosniacki GG, Zannin PHT. Framework to manage railway noise exposure in Brazil based on field measurements and strategic noise mapping at the local level. Sci Total Environ. 2021;757: 143721. https://doi.org/10.1016/j.scitotenv.2020.143721.

22. Aumond P, Can A, Mallet V, Gauvreau B, Guillaume G. Global sensitivity analysis for road traffic noise modelling. Appl Acoust. 2021;176:107899. https://doi.org/10.1016/j.apacoust.2020. 107899.

23. Selamat FE, Tagusari J, Matsui T. Mapping of transportation noise-induced health risks as an alternative tool for risk communication with local residents. Appl Acoust. 2021;178:107987. https://doi.org/10.1016/j.apacoust.2021.107987.

24. Nourmohammadi Z, Lilasathapornkit T, Ashfaq M, Gu Z, Saberi M. Mapping urban environmental performance with emerging data sources: a case of urban greenery and traffic noise in Sydney, Australia. Sustainability. 2021;13:605. https://doi.org/ 10.3390/su13020605.

25. Kim P, Ryu H, Jeon J-J, Chang SI. Statistical road-traffic noise mapping based on elementary urban forms in two cities of South Korea. Sustainability. 2021;13:2365. https://doi.org/10.3390/ su13042365.

26. Arbaoui I, Hamou A, Abderrahim H, Tayeb A, Sayad N, Arbaoui A. Comparative study of the noise generated by the motocompressor and that generated by the turbo-compressor. J Fundam Appl Sci. 2018;10(1):201-15. https://doi.org/10.4314/ jfas.v10i1.15.

27. Mendonça KT, Leite JC, Evaluation of acoustics in the built environment, mapping and estimation of noise in the stamping sector of a metallurgical industry, Int J Adv Eng Res Sci 6, 2 2019, https://doi.org/10.22161/ijaers.6.2.34 
28. Seutche JC, Nsouandélé JL, Njingti-N, et al. Geographical mapping and modelling of noise pollution from industrial motors: a case study of the Mbalmayo Thermal Power Plant in Cameroon. Environ Monit Assess. 2019;191:765. https://doi.org/10.1007/ s10661-019-7940-z.

29. Tomozeı C, Pipa A, Irımı O, Panainte-Lehadus M, Nedeff F. Measuring noise level in the textile industry. J Eng Stud Res. 2018;24(4):43-9 Retrieved from http://jesr.ub.ro/1/article/view/ 48.

30. Lim MH, Lee YL, Lee FW, Heng C. Strategic noise mapping prediction for a rubber manufacturing factory in Malaysia. Int Conf Civil Environ Eng (ICCEE 2018). 2018;65:05019. https:// doi.org/10.1051/e3sconf/20186505019.

31. NIOSH, "National Institute for Occupational Safety and Health (NIOSH)" (1998) Criteria for a recommended standard: occupational noise exposure: revised criteria

32. Ahmed SS, Gadelmoula AM. Industrial noise monitoring using noise mapping technique: a case study on a concrete block-making factory. Int J Environ Sci Technol. 2020. https://doi.org/10.1007/ s13762-020-02982-9.

33. Maheswaran K, Serrao NG, Murugan SS, Prabaharan T. Acoustic level measurement by noise mapping method and mitigation using acoustic plaster in power press industry. Int J Adv Sci Technol. 2020;29(7):11200-7 Retrieved from http://sersc.org/journals/ index.php/IJAST/article/view/27539.

34. Pramendra D, Vartika S. Environmental noise pollution monitoring and impacts on human health in Dehradun City, Uttarakhand, India. Civil Environ Res. 2011;1:1 ISSN 2224-5790 (Print) ISSN 2225-0514 (Online), Retrieved from https://www.iiste.org/ Journals/index.php/CER/article/view/729.

35. Gómez Comendador VF, Arnaldo Valdés RM, Lisker B. A holistic approach to the environmental certification of green airports. Sustainability. 2019;11:4043. https://doi.org/10.3390/ sul1154043.

36. Zannin PHT, Sant'Ana DQ. Noise mapping at different stages of a freeway redevelopment project - a case study in Brazil. Appl Acoust. 2011;72(8):479-86. https://doi.org/10.1016/j.apacoust. 2010.09.014

37. European Environment Agency report No 22/2019, Environmental noise in Europe - 2020, European Environment Agency, 2020, ISBN 978-92-9480-209-5, ISSN 1977-8449, doi:https://doi.org/10.2800/686249, Retrieved from https://www.eea.europa.eu/publications/environmental-noise-ineurope

38. ISO 9613-2, Acoustics, Attenuation of sound during propagation outdoors, Part 2: General method of calculation. 1996

39. ISO 9613-1, Acoustics - Attenuation of sound during propagation outdoors - Part 1: Calculation of the absorption of sound by the atmosphere, 1993

40. ISO 8297, Acoustics - Determination of sound power levels of multisource industrial plants for evaluation of sound pressure levels in the environment - Engineering method. 1994

41. ISO 3744, Acoustics - Determination of sound power levels and sound energy levels of noise sources using sound pressure Engineering methods for an essentially free field over a reflecting plane, 2010

42. ISO 3746, Acoustics - Determination of sound power levels and sound energy levels of noise sources using sound pressure Survey method using an enveloping measurement surface over a reflecting plane, 2010

43. ISO 10140-2 Acoustics - Laboratory measurement of sound insulation of building elements - Part 2: Measurement of airborne sound insulation. 2010

44. ISO 16283-1, Acoustics - Field measurement of sound insulation in buildings and of building elements - Part 1: Airborne sound insulation. 2014
45. ISO 16283-3, Acoustics - Field measurement of sound insulation in buildings and of building elements - Part 3: Façade sound insulation. 2016

46. ISO 717-1, Acoustics - Rating of sound insulation in buildings and of building elements - Part 1: Airborne sound insulation. 2013

47. Gómez DMM, Jaramillo AM, Ochoa J. Analysis of the measurement uncertainty and its effects on noise mapping validations. J Environ Manag. 2020;266:110606. https://doi.org/10.1016/j. jenvman.2020.110606.

48. Zannin PHT, Do Nascimento EO, Da Paz EC, Do Valle F. Application of artificial neural networks for noise barrier optimization. Environments. 2018;5:135. https://doi.org/10.3390/ environments5120135.

49. Bernardini M, Fredianelli L, Fidecaro F, Gagliardi P, Nastasi M, Licitra G. Noise assessment of small vessels for action planning in canal cities. Environments. 2019;6:31. https://doi.org/10.3390/ environments6030031.

50. Butorina M, Shabarova A and Kuklin D, Noise zoning of the city using noise mapping, 2020 IEEE Conference of Russian Young Researchers in Electrical and Electronic Engineering (EIConRus), St. Petersburg and Moscow, Russia, 2020, pp. 1495-1497, doi: https://doi.org/10.1109/EIConRus49466.2020.9039022, Retrieved from https://ieeexplore.iee.org/document/9039022

51. Moravec M, Badida M, Mikušová N, Sobotová L, Švajlenka J, Dzuro T. Proposed options for noise reduction from a wastewater treatment plant: case study. Sustainability. 2021;13:2409. https:// doi.org/10.3390/su13042409.

52. Jung S, Kang H, Choi J, Hong T, Park HS. Quantitative health impact assessment of construction noise exposure on the nearby region for noise barrier optimization. Build Environ. 2020;176: 106869. https://doi.org/10.1016/j.buildenv.2020.106869.

53. Lokhande SK, Dhawale SA, Pathak SS, Gautam R, Jain MC, Bodhe GL. Appraisal of noise level dissemination surrounding mining and industrial areas of Keonjhar, Odisha: a comprehensive approach using noise mapping. Arch Acoustics. 2017;42(3):42332. https://doi.org/10.1515/aoa-2017-0044.

54. Yuan M, Yin C, Sun Y, Chen W. Examining the associations between urban built environment and noise pollution in highdensity high-rise urban areas: a case study in Wuhan, China. Sustain Cities Soc. 2019;50:101678. https://doi.org/10.1016/j. scs.2019.101678.

55. Zhang W, Liu E, Png CE. A framework for community noise modelling using machine learning methods. Appl Acoust. 2020;157(1):107033. https://doi.org/10.1016/j.apacoust.2019. 107033.

56. WG-AEN: Assessment of exposure to noise. Good practice guide for strategic noise mapping and the production of associated data on noise exposure, Version 2. European Commission Working Group, 2007

57. Fredianelli L, Bolognese M, Fidecaro F, Licitra G. Classification of noise sources for port area noise mapping. Environments. 2021;8(2):12. https://doi.org/10.3390/environments8020012.

58. Čurović L, Jeram S, Murovec J, Novaković T, Rupnik K, Prezelj J. Impact of COVID-19 on environmental noise emitted from the port. Sci Total Environ. 2021;756(20):144147. https://doi.org/10. 1016/j.scitotenv.2020.144147.

59. Basu B, Murphy E, Molter A, Basu AS, Sannigrahi S, Belmonte $M$, et al. Investigating changes in noise pollution due to the COVID-19 lockdown: the case of Dublin, Ireland. Sustain Cit Soc. 2021;65:102597. https://doi.org/10.1016/j.scs.2020.102597.

60. Morel J, Marquis-Favre C, Gille L-A. Noise annoyance assessment of various urban road vehicle pass-by noises in isolation and combined with industrial noise: a laboratory study. Appl Acoust. 2016;101:47-57. https://doi.org/10.1016/j.apacoust.2015.07.017. 
61. Marquis-Favre C, Morel J. A simulated environment experiment on annoyance due to combined road traffic and industrial noises. Int J Environ Res Public Health. 2015;12:8413-33. https://doi. org/10.3390/ijerph120708413.

62. ISO 1996-1 Acoustics - Description, measurement and assessment of environmental noise - Part 1: Basic quantities and assessment procedures, 2016

63. ISO 1996-2Acoustics - Description, measurement and assessment of environmental noise - Part 2: Determination of sound pressure levels, 2017

64. Rosmala OP, Santoso TB, Huda M. Acoustic noise mapping on various location in Surabaya. Surabaya: 2019 International Electronics Symposium (IES); 2019. p. 148-53. https://doi.org/ 10.1109/ELECSYM.2019.8901649. Retrieved from https:// ieeexplore.ieee.org/document/8901649

65. Chi THM, Ketsakorn A, Chaikittiporn C, Toai NP. Associations between environmental noise mapping and self-concerned from noise in Can Tho community, Vietnam. Sci Technol Asia. 2017;22(3):126-33 Retrieved from https://ph02.tci-thaijo.org/ index.php/SciTechAsia/article/view/102118.

66. Alam P, Ahmad K, Afsar S, Akhter N. Noise monitoring, mapping, and modelling studies - a review. J Ecol Eng. 2020;21(4): 82-93. https://doi.org/10.12911/22998993/119804.

67. Kalawapudi K, Singh T, Dey J, Vijay R, Kumar R. Noise pollution in Mumbai Metropolitan Region (MMR): An emerging environmental threat. Environ Monit Assess. 2020;192:152. https:// doi.org/10.1007/s10661-020-8121-9.

68. Paschalidou AK, Kassomenos P, Chonianaki F, Valkouma T. 3year noise monitoring and strategic noise mapping in an extended motorway. Environ Sci Pollut Res. 2019;26:15608-16. https://doi. org/10.1007/s11356-019-04966-w.

69. Bulkin VV, Khromulina TD, Kirillov IN. Analysis of the acoustically noise situation in an urbanized area in the presence of vehicular and industrial noise. IOP Conf Series: Earth and Environmental Science. 2019;272:022237. https://doi.org/10. 1088/1755-1315/272/2/022237 Retrieved from https:// iopscience.iop.org/article/10.1088/1755-1315/272/2/022237/ meta.

70. Bite PZ, Sillo S, Long-term noise monitoring and dynamic noise mapping - a case study, Euronoise 2018, Crete, 1313 -1338, ISSN: 2226-5147

71. Xu C, Yiwen Z, Cheng B, Li L, Zhang M. Study on environmental Kuznets Curve for noise pollution: a case of 111 Chinese cities. Sustain Cities Soc. 2020;63:102493. https://doi.org/10.1016/j.scs. 2020.102493

72. Picaut J, Fortin N, Bocher E, Petit G, Aumond P. An open-science crowdsourcing approach for producing community noise maps using smartphones. Build Environ. 2019;148(15):20-33. https:// doi.org/10.1016/j.buildenv.2018.10.049.

73. Lee HP, Garg S, Lim KM. Crowdsourcing of environmental noise map using calibrated smartphones. Appl Acoust. 2020;160: 107130. https://doi.org/10.1016/j.apacoust.2019.107130.

74. Marques G., Pitarma R. (2019) Noise mapping through mobile crowdsourcing for enhanced living environments. In: Rodrigues $\mathrm{J}$ et al. (eds) Computational Science - ICCS 2019. ICCS 2019. Lecture Notes in Computer Science, vol 11538. Springer, Cham. https://doi.org/10.1007/978-3-030-22744-9_52

75. Liu Y et al., "Internet of Things for Noise Mapping in Smart Cities: State of the Art and Future Directions," in IEEE Network, vol. 34, no. 4, pp. 112-118, 2020, https://doi.org/10. 1109/MNET.011.1900634.

76. Fan X, Zhao L, He H, Zhang D, Ren Z, Zhang Y. Environmental noise pollution control of substation by passive vibration and acoustic reduction strategies. Appl Acoust. 2020;165:107305. https://doi.org/10.1016/j.apacoust.2020.107305.
77. Prabu M, Gokulram M, Magibalan S, Senthilkumar P, Boopathi R. Noise mapping-in glass manufacturing industry. Int Educ J Sci Eng (IEJSE). 2018;1(3):12-7 E-ISSN NO: 2581-6195, Retrieved from http://www.iejse.com/journal/index.php/iejse/article/view/ 18.

78. Morillas JMB, Gozalo GR, González DM, Moraga PA, VílchezGómez R. Noise pollution and urban planning. Curr Pollut Rep. 2018;4:208-19. https://doi.org/10.1007/s40726-018-0095-7.

79. Kotzen B, English C, Environmental noise barriers, 2nd edition, , Taylor \& Francis Group, ISBN 0-203-93138-6 Master e-book ISBN, ISBN10: 0-203-93138-6 (ebook), ISBN13: 978-0-20393138-7 (ebook), 2009

80. Margaritis E, Kang J. Relationship between urban green spaces and other features of urban morphology with traffic noise distribution. Urban Urban Green. 2016;15:174-85. https://doi.org/10. 1016/j.ufug.2015.12.009.

81. Margaritis E, Kang J. Relationship between green space-related morphology and noise pollution. Ecol Indic. 2017;72:921-33. https://doi.org/10.1016/j.ecolind.2016.09.032.

82. Jaramillo AM, Stell C, (2015), Architectural Acoustics, Taylor \& Francis Group, ISBN: 978-1-315-75284-6 (ebk), ISBN: 978-0415-73214-7 (pbk), ISBN: 978-1-315-75284-6 (ebk)

83. Paschalidou AK, Kassomenos P, Chonianaki F. Strategic Noise Maps and Action Plans for the reduction of population exposure in a Mediterranean port city. Sci Total Environ. 2019;654:144-53. https://doi.org/10.1016/j.scitotenv.2018.11.048.

84. Kanellis M, de Jong MM, Slooff L, Debije MG. The solar noise barrier project: 1. Effect of incident light orientation on the performance of a large-scale luminescent solar concentrator noise barrier. Renew Energy. 2017;103:647-52. https://doi.org/10.1016/j. renene.2016.10.078

85. Bognár Á, Kusnadi S, Slooff LH, Tzikas C, Loonen RCGM, de Jong MM, et al. The solar noise barrier project 4: Modeling of fullscale luminescent solar concentrator noise barrier panels. Renew Energy. 2020;151:1141-9. https://doi.org/10.1016/j.renene.2019. 11.102 .

86. Licitra G, Vogiatzis K. Preface: New Solutions Mitigating Environmental Noise Pollution. Environments. 2019;6:117. https://doi.org/10.3390/environments6110117.

87. ISO 10534-2: Acoustics - determination of sound absorption coefficient and impedance in impedance tubes-Part 2: transferfunction method, 1998

88. Gandoman M, Kokabi M. Sound barrier properties of sustainable waste rubber/geopolymer concretes, Iran. Polym J. 2016;24(2): 105-12. https://doi.org/10.1007/s13726-014-0304-1.

89. Bozkurt TS, Demirkale SY. Laboratory analyses and numerical simulation for sound absorption of plasters in historical buildings. J Cult Herit. March-April 2019;36:103-17. https://doi.org/10. 1016/j.culher.2018.09.012.

90. Bozkurt TS, Demirkale SY. The laboratory analyses for the plasters prepared with river sand aggregate and hydraulic lime binder. Constr Build Mater. 2018;190:691-709. https://doi.org/10.1016/j. conbuildmat.2018.09.073.

91. Bozkurt TS, Demirkale SY. Investigation and development of sound absorption of plasters prepared with pumice aggregate and natural hydraulic lime binder. Appl Acoust. 2020;170(15): 107521. https://doi.org/10.1016/j.apacoust.2020.107521.

92. Bozkurt TS, Demirkale SY. The experimental research of sound absorption in plasters produced with perlite aggregate and natural hydraulic lime binder. Acoust Aust. 2020;48:375-93. https://doi. org/10.1007/s40857-020-00203-4.

93. Bozkurt TS, Investigation and development of sound absorption coefficient of plaster surface coatings used in historical place. $\mathrm{PhD}$ thesis, Istanbul Technical University, Graduate School of Science, Engineering and Technology (2019) 
94. Corredor-Bedoya AC, Zoppi RA, Serpa AL. Composites of scrap tire rubber particles and adhesive mortar - noise insulation potential. Cem Concr Compos. 2017;82:45-66. https://doi.org/10.1016/ j.cemconcomp.2017.05.007.

95. Mohammed BS, Hossain KMA, Swee JTE, Wong G, Abdullahi M. Properties of crumb rubber hollow concrete block. J Clean Prod. 2012;23:57-67. https://doi.org/10.1016/j.jclepro.2011.10. 035.

96. Pastor JM, García LD, Quintana S, Peña J. Glass reinforced concrete panels containing recycled tyres: evaluation of the acoustic properties of for their use as sound barriers. Constr Build Mater. 2014;54:541-9. https://doi.org/10.1016/j.conbuildmat.2013.12. 040 .

97. Medina FN, Flores-Medina D, Hernández-Olivaresa F. Influence of fibers partially coated with rubber from tire recycling as aggregate on the acoustical properties of rubberized concrete. Constr Build Mater. 2016;129:25-36. https://doi.org/10.1016/j. conbuildmat.2016.11.007.

98. Holmes N, Browne A. Acoustic properties of concrete panels with crumb rubber as a fine aggregate replacement. Constr Build Mater. 2014;73:195-204. https://doi.org/10.1016/j.conbuildmat.2014. 09.107 .

99. Sukontasukkul P. Use of crumb rubber to improve thermal and sound properties of pre-cast concrete panel. Constr Build Mater. 2009;23(2):1084-92. https://doi.org/10.1016/j.conbuildmat.2008. 05.021 .

100. Chu L, Fwa TF, Tan KH. Evaluation of wearing course mix designs on sound absorption improvement of porous asphalt pavement. Constr Build Mater. 2017;141(15):402-9. https://doi.org/ 10.1016/j.conbuildmat.2017.03.027.
101. Vaitkus A, Andriejauskas T, Vorobjovas V, Jagniatinskis A, Fiks B, Zofka E. Asphalt wearing course optimization for road traffic noise reduction. Constr Build Mater. 2017;152(15):345-56. https://doi.org/10.1016/j.conbuildmat.2017.06.130.

102. Wang Z, Xie J, Gao L, Liu M, Liu Y. Improvement of acoustic model and structural optimization design of porous asphalt concrete based on meso-structure research. Constr Build Mater. 2020;265(30):120327. https://doi.org/10.1016/j.conbuildmat. 2020.120327.

103. Chu L, Fwa TF, Tan KH. Laboratory evaluation of sound absorption characteristics of pervious concrete pavement materials. Transp Res Rec. 2017;2629(1):91-103. https://doi.org/10.3141/ 2629-12.

104. Shen D-H, Wu D-H, Du J-C. Laboratory investigation of basic oxygen furnace slag for substitution of aggregate in porous asphalt mixture. Constr Build Mater. 2009;23(1):453-61. https://doi.org/ 10.1016/j.conbuildmat.2007.11.001.

105. Zhao C, Wang P, Wang L, Liu D. Reducing railway noise with porous sound-absorbing concrete slabs. Adv Mater Sci Eng. 2014;2014(11):1-11. https://doi.org/10.1155/2014/206549.

106. Oancea I, Bujoreanu C, Budescu M, Benchea M, Grădinaru MC. Considerations on sound absorption coefficient of sustainable concrete with different waste replacements. J Clean Prod. 2018;203: 301-12. https://doi.org/10.1016/j.jclepro.2018.08.273.

Publisher's Note Springer Nature remains neutral with regard to jurisdictional claims in published maps and institutional affiliations. 